\title{
Upregulation of TRPC1 Contributes to Contractile Function in Isoproterenol- induced Hypertrophic Myocardium of Rat
}

\author{
Mo-Si Chen ${ }^{a, b}$ Jun-Hua Xiao a,b Yong Wang ${ }^{a}$ Bo-Ming Xua Lu Gao \\ Jia-Ling Wanga,b \\ aDepartment of Pharmacology, Tongji Medical College, Huazhong University of Science and \\ Technology, ${ }^{\mathrm{b}}$ The Key Laboratory for Drug Target Researches and Pharmacodynamic Evaluation of \\ Hubei Province, Wuhan, People's Republic of China
}

\section{Key Words}

Transient receptor potential canonical channel 1 - Stretch-activated ion channels $\bullet$ Hypertrophic myocardium • Contractile function

\begin{abstract}
Aims: The transient receptor potential canonical channel 1 (TRPC1) is a crucial component of the stretch-activated ion channels (SACs). The objective of this research was to demonstrate the contribution of TRPC1 in maintaining cardiac contractile function in the hypertrophic myocardium. Methods: Hypertrophic rat hearts were induced by injecting isoproterenol intraperitoneally, and the expressions of TRPC1/3/6 and $\mathrm{Na}^{+} / \mathrm{Ca}^{2+}$ exchanger 1 (NCX1) proteins were analyzed by Western blot. The intracellular calcium images, the action potential of myocardium, the length-dependent contractile force of ventricle muscle and the cardiac output of isolated heart were investigated. Results: The expression of TRPC1 was increased in the hypertrophic myocardium. After being stretched, the ascendant amplitude of the increase in the intracellular calcium ion concentration $\left(\left[\mathrm{Ca}^{2+}\right]_{i}\right)$ in the hypertrophic myocardium was higher than that in the normal myocardium. The increase of the $\mathrm{APD}_{50}$ and the amplitude of the membrane potential depolarization were more significant in the hypertrophic myocardium after the activation of SACs. When the heart preparations were perfused with Tyrode's solution, there was no difference in the cardiac systolic function between the cardiac hypertrophy group and the control group. Gadolinium, a SACs blocker, reduced the length-dependent contractile force and suppressed the ascending limb of the Frank-Starling curves in the hypertrophic heart. Conclusions: The upregulation of TRPC1 contributes to the contractile function in the hypertrophic myocardium by increasing $\left[\mathrm{Ca}^{2+}\right]_{i}$ through the SACs.
\end{abstract}




\section{Introduction}

The transient receptor potential canonical channels (TRPCs) are a class of cation channels that regulate $\mathrm{Ca}^{2+}$ influx in the myocardium [1]. TRPC1 and TRPC6 are considered to be participants of the stretch-activated ion channels (SACs), which are permeable to $\mathrm{Na}^{+}, \mathrm{K}^{+}$ and $\mathrm{Ca}^{2+}$. The stretch-activated current $\left(I_{\mathrm{SAC}}\right)$ increases with the upregulation of TRPC1 $[2,3]$. The TRPC3 channels colocalize with the $\mathrm{Na}^{+} / \mathrm{Ca}^{2+}$ exchanger 1 (NCX1), and the TRPC3-NCX1 signaling complex is a pivotal mechanism for the control of cardiac $\mathrm{Ca}^{2+}$ homeostasis during cardiomotility $[4,5]$. When the heart muscle is stretched, the contractile force increases. The main explanation for this mechanism is that stretching augments the effect of changes in the overlap between the thin and thick filaments [6]. Gadolinium chloride $\left(\mathrm{Gd}^{3+}\right)$, a SACs blocker, reduced the ventricle contractile force more obviously in the longer muscle lengths than in the shorter muscle lengths [7]. The data indicated that the cations entering from the SACs contribute to the length-dependent contractile force, but the role of the SACs on cardiac systolic function remains controversial [8].

The expression of TRPC1 was increased in the hypertrophied myocardium $[9,10]$, and the amplitude of $I_{\mathrm{SAC}}$ in the ventricular myocytes was increased with hypertrophy [11], but the significance of TRPC1 for cardiac contractile function remains unclear. In this study, we investigated the role of TRPC1 on length-dependent contractile function in the isoproterenolinduced hypertrophic myocardium of rat, and our results demonstrated that upregulation of TRPC1 contributes to contractile function in the hypertrophic myocardium by increasing intracellular calcium ion concentration $\left(\left[\mathrm{Ca}^{2+}\right]_{\mathrm{i}}\right)$ through the SACs.

\section{Materials and Methods}

\section{Rat model of cardiac hypertrophy}

The Animal Ethics Committee of Huazhong University of Science and Technology approved the study protocol. The investigation conforms to the Guide for the Care and Use of Laboratory Animals published by the US National Institutes of Health (NIH Publication No. 85-23, revised 1985).

Male Sprague-Dawley rats $(250-280 \mathrm{~g})$ were randomly divided into the cardiac hypertrophy $(\mathrm{CH})$ group and the control group. The $\mathrm{CH}$ group rats were administered isoproterenol $5 \mathrm{mg} / \mathrm{kg}$ for 5 days, once daily by intraperitoneal injection [12]. The control group rats received saline solution $(0.9 \% \mathrm{NaCl})$. All the rats were kept under standard conditions with free access to food and water for 5 weeks since the first injection [13].

\section{Morphological examination}

The rats were weighed and anesthetized. The hearts were excised and weighed in an analytical balance. All the samples from identical part of every rat left ventricles were prepared for the paraffin sections, and then stained with hematoxylin and eosin for the light microscopic evaluation. The mean myocyte diameter was calculated from each section with software Image-Pro Plus 6.0 (Media Cybernetics, USA).

\section{Western blot analysis}

The expression of TRPC1/3/6 and NCX1 proteins were determined by Western blot. The proteins were extracted from the identical part of the rat left ventricles in the $\mathrm{CH}$ and control groups. The protein samples $(70 \mu \mathrm{g})$ were separated by $8 \%$ SDS-PAGE. Polyclonal rabbit anti-TRPC1, anti-TRPC3 and anti-TRPC6 antibodies (Alomone Labs, Israel), anti-NCX1 and anti-GAPDH antibodies (Santa Cruz Biotechnology, USA) were used.

\section{Calcium imaging}

The ventricular myocytes were freshly isolated, using a collagenase-protease dispersion method [9]. The myocytes were used within $6 \mathrm{~h}$ of harvesting, and only typical $\mathrm{Ca}^{2+}$-tolerant, rod-shaped cells were selected for analysis. The cells were incubated with Tyrode's solution containing $5 \mu \mathrm{mol} / \mathrm{L}$ Fura-2/ AM (Invitrogen, USA) for $30 \mathrm{~min}$ at room temperature. After being washed three times and incubated in 
isotonic (1.0 T) extracellular solution for $30 \mathrm{~min}$, the cells were illuminated using a calcium imaging system (TILL Photonics, Germany). The fluorescence signal was recorded as previously described [14].

After the $1.0 \mathrm{~T}$ extracellular solution was replaced by the hypotonic $(0.6 \mathrm{~T})$ extracellular solution, the cells swelled because of the hyposmotic solution and the cytomembrane was stretched $[15,16]$. The changes in $\left[\mathrm{Ca}^{2+}\right]_{i}$ were displayed as a ratio of the fluorescence relative to the intensity before the application of the hypotonic extracellular solution $\left(\mathrm{F} / \mathrm{F}_{0}\right)$. The protocol was repeated three times with the new myocyte chambers as follows: (i). in the extracellular solution containing the L-type $\mathrm{Ca}^{2+}$ channel inhibitor, verapamil (Ver $0.1 \mu \mathrm{mol} / \mathrm{L}$ ); (ii). in the extracellular solution containing the SACs blocker, gadolinium chloride $\left(\mathrm{Gd}^{3+}\right.$ $10 \mu \mathrm{mol} / \mathrm{L})$ [17]; (iii). in the extracellular solution containing the NCX inhibitor, nickel chloride $\left(\mathrm{Ni}^{2+} 5.0\right.$ mmol/L) [18]. The extracellular solutions contained (mmol/L): $65 \mathrm{NaCl}, 5 \mathrm{KCl}, 2.5 \mathrm{CaCl}_{2}, 0.5 \mathrm{MgSO}_{4}, 10$ glucose, 10 HEPES, 130 (1.0T) or 17 (0.6T) mannitol (pH 7.4). An osmolarity of $296 \mathrm{mOsm} /$ liter was taken as isotonicity (1.0 T), and $178 \mathrm{mOsm} /$ liter was taken as hypotonicity (0.6 T) [15].

\section{Action potential recording}

The papillary muscles were excised from the right ventricles, both ends of the muscle were tied a knot, and the working muscle between two knots was $3.0 \mathrm{~mm}$. One knot was fixed in the center of a perspex chamber, and the other knot was attached to a micrometer for length adjustments. The preparations were perfused with Tyrode's solution $\left(8 \mathrm{ml} / \mathrm{min}, 37^{\circ} \mathrm{C}\right)$ containing (mmol/L): $137 \mathrm{NaCl}, 2.7 \mathrm{KCl}, 1.8 \mathrm{CaC1}_{2}, 1.0$ $\mathrm{MgCl}_{2}, 12 \mathrm{NaHCO}_{3}, 0.4 \mathrm{NaH}_{2} \mathrm{PO}_{4}, 5.6$ glucose (pH 7.4), saturated with $95 \% \mathrm{O}_{2}$ and $5 \% \mathrm{CO}_{2}$.

The action potential (AP) was recorded through a glass microelectrode inserted into the myocyte, using a standard microelectrode recording technique [19]. The glass microelectrode contained a $3 \mathrm{~mol} / \mathrm{L}$ $\mathrm{KCl}$ solution and had a tip resistance of 10-15 $\mathrm{M} \Omega$. The muscles were stimulated with a pair of platinum electrodes at the pacing rate of $0.2 \mathrm{~Hz}$. The AP signals were placed into a microelectrode amplifier and recorded by a computer system (Chengyi, China). The muscles were first set to the original length without stretch $\left(L_{0}\right)$. Then, the papillary muscles were stretched to an increase of $10 \%$ of the length [11]. The length of $110 \% \mathrm{~L}_{0}$ was defined as $1.1 \mathrm{~L}_{0}$. The experiments were repeated to observe the effects of $10 \mu \mathrm{mol} / \mathrm{L} \mathrm{Gd}^{3+}$ and $0.1 \mu \mathrm{mol} / \mathrm{L}$ Ver on the AP.

\section{Contractile force of myocardium}

The preparations of left ventricle papillary muscle were mounted in a muscle chamber and perfused in Tyrode's solution. The muscles were stimulated with a pair of platinum electrodes at the pacing rate of $0.2 \mathrm{~Hz}$ to obtain isometric force. The signals were recorded by a force transducer (Chengyi, China). The contractile force of myocardium was observed at the lengths of $\mathrm{L}_{0}$ and $1.1 \mathrm{~L}_{0}$. The experiment was repeated to observe the effects of $10 \mu \mathrm{mol} / \mathrm{L} \mathrm{Gd}^{3+}$ and $0.1 \mu \mathrm{mol} / \mathrm{L}$ Ver on the cardiac contractility of the preparations before and after being stretched.

\section{Isolated working heart preparation}

The Langendorff models of rat hearts were prepared as previously described [20] and perfused with Tyrode's solution. The perfusion fluid was guided through the left atrial cannula to the left ventricle (the basic ventricular preload was $10 \mathrm{cmH}_{2} \mathrm{O}$ filling pressure), which ejected the fluid out against an afterload of $80 \mathrm{cmH}_{2} \mathrm{O}$. The cardiac output was recorded at different ventricular preloads. Frank-Starling curves of the relationship between the ventricular preload and the stroke volume were drawn. The changes of curves were observed when the SACs were blocked by $10 \mu \mathrm{mol} / \mathrm{L} \mathrm{Gd}^{3+}$.

\section{Statistical analysis}

The experimental results were analyzed with analysis of variance. The results are expressed as the means \pm standard error of the mean (SE). The values of $P<0.05$ were considered to be statistically significant.

\section{Results}

Expression of TRPC1, TRPC3, TRPC6 and NCX1 in hypertrophic myocardium

The overall mortality after 5 weeks of isoproterenol administration was $30 \%$. Cardiac hypertrophy was observed in the ventricles. The mean myocyte diameter of the $\mathrm{CH}$ group 
Table 1. Diameter of cardiomyocyte, body and heart weights after 5 weeks of isoproterenol administration. Values are the means \pm SE. Cardiac index $=$ heart weight $/$ body weight, LVW = left ventricle weight, BW = body weight, RVW = right ventricle weight, LAW = left atrium weight, RAW = right atrium weight; $\mathrm{n}=10$ per group, $* P<0.05$ vs. control

\begin{tabular}{lll}
\hline & Control & Cardiac hypertrophy \\
\hline Diameter of cardiomyocyte $(\mu \mathrm{m})$ & $13.06 \pm 1.08$ & $16.51 \pm 1.28^{*}$ \\
Body weight $(\mathrm{g})$ & $406.50 \pm 11.79$ & $365.10 \pm 13.75^{*}$ \\
Cardiac index $(\mathrm{mg} / \mathrm{g})$ & $2.39 \pm 0.14$ & $3.08 \pm 0.18^{*}$ \\
LVW/BW $(\mathrm{mg} / \mathrm{g})$ & $1.76 \pm 0.08$ & $2.25 \pm 0.15^{*}$ \\
RVW/BW $(\mathrm{mg} / \mathrm{g})$ & $0.45 \pm 0.07$ & $0.59 \pm 0.09^{*}$ \\
LAW/BW $(\mathrm{mg} / \mathrm{g})$ & $0.08 \pm 0.02$ & $0.11 \pm 0.03^{*}$ \\
RAW/BW $(\mathrm{mg} / \mathrm{g})$ & $0.09 \pm 0.02$ & $0.12 \pm 0.03^{*}$ \\
\hline
\end{tabular}

Fig. 1. Western blot analyses of TRPC1/3/6 and NCX1 protein expression in hearts. The statistical data are shown by the relative density ratio of TRPC1/3/6 and NCX1 to the GAPDH band. The data presented are representative of ten separate hearts from the control (Con) and cardiac hypertrophy $(\mathrm{CH})$ groups. $* P<0.05$ vs. Con.

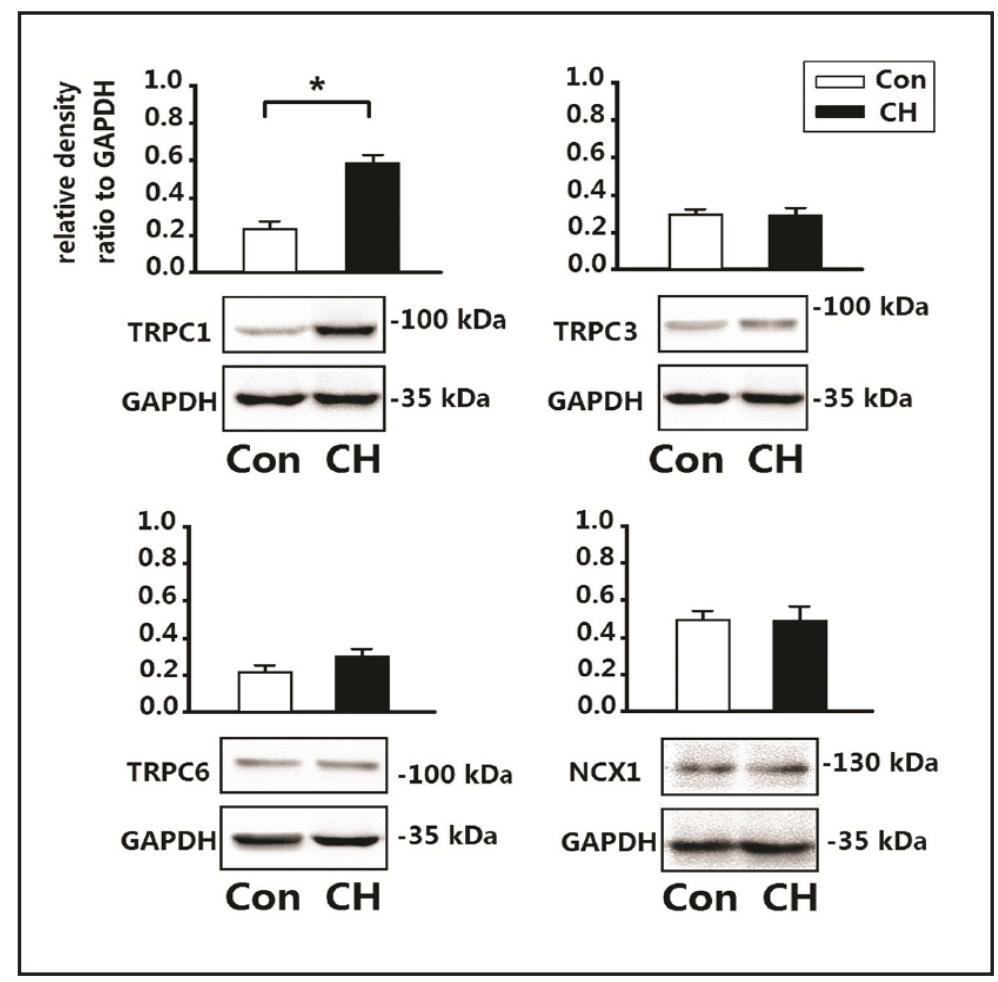

was more than that of the control group. The biometric parameters in the surviving rats were presented in Table 1 . The atria and ventricles were significantly hypertrophied in the $\mathrm{CH}$ group of rats. The Western blot analysis revealed that the expression of TRPC1 was upregulated in the CH group, while the levels of TRPC3, TRPC6 and NCX1 remained stationary. The data were consistent with previous reports $[10,21]$, and were shown in Fig. 1.

Increase of intracellular calcium induced by stretching cytomembrane

After the $1.0 \mathrm{~T}$ extracellular solution was replaced by the $0.6 \mathrm{~T}$ extracellular solution, the cytomembrane was stretched by hyposmotic cell swelling, the SACs were activated and $\left[\mathrm{Ca}^{2+}\right]_{\mathrm{i}}$ was increased. The ascendant amplitude of $\left[\mathrm{Ca}^{2+}\right]_{\mathrm{i}}$ increase in the hypertrophic myocardium was obviously higher ( $\mathrm{CH} 30.75 \pm 4.16 \%$ vs. control $11.65 \pm 1.43 \%, P<0.05$ ). The data of typical cells were shown in Fig. 2. The administration of $\mathrm{Gd}^{3+}$ and $\mathrm{Ni}^{2+}$ suppressed the increase of $\left[\mathrm{Ca}^{2+}\right]_{\mathrm{i}}$ in both groups, and Ver had no effect. 
Fig. 2. Hyposmotic cell swelling induced $\mathrm{Ca}^{2+}$ influx. The ascendant amplitude of $\left[\mathrm{Ca}^{2+}\right]_{\mathrm{i}}$ in the cardiac hypertrophic $(\mathrm{CH})$ myocardium was obviously higher than control (Con) group in the empty bathing solution (EBS). $\mathrm{Gd}^{3+}$ (10 $\mu \mathrm{mol} / \mathrm{L})$ and $\mathrm{Ni}^{2+}(5.0$ $\mathrm{mmol} / \mathrm{L}$ ) suppressed the increase of $\left[\mathrm{Ca}^{2+}\right]_{\mathrm{i}}$ in both Con and $\mathrm{CH}$ groups separately, and verapamil (Ver $0.1 \mu \mathrm{mol} / \mathrm{L}$ ) had no effect. The numbers above the bar graphs denote the number of cells analyzed. An osmolarity of 296 mOsm/ liter was taken as isotonicity $(1.0 \mathrm{~T})$, and $178 \mathrm{mOsm} /$ liter was taken as hypotonicity $(0.6 \mathrm{~T}) .{ }^{*} P<0.05$ vs. Con; $\# P<0.05$ vs. EBS.

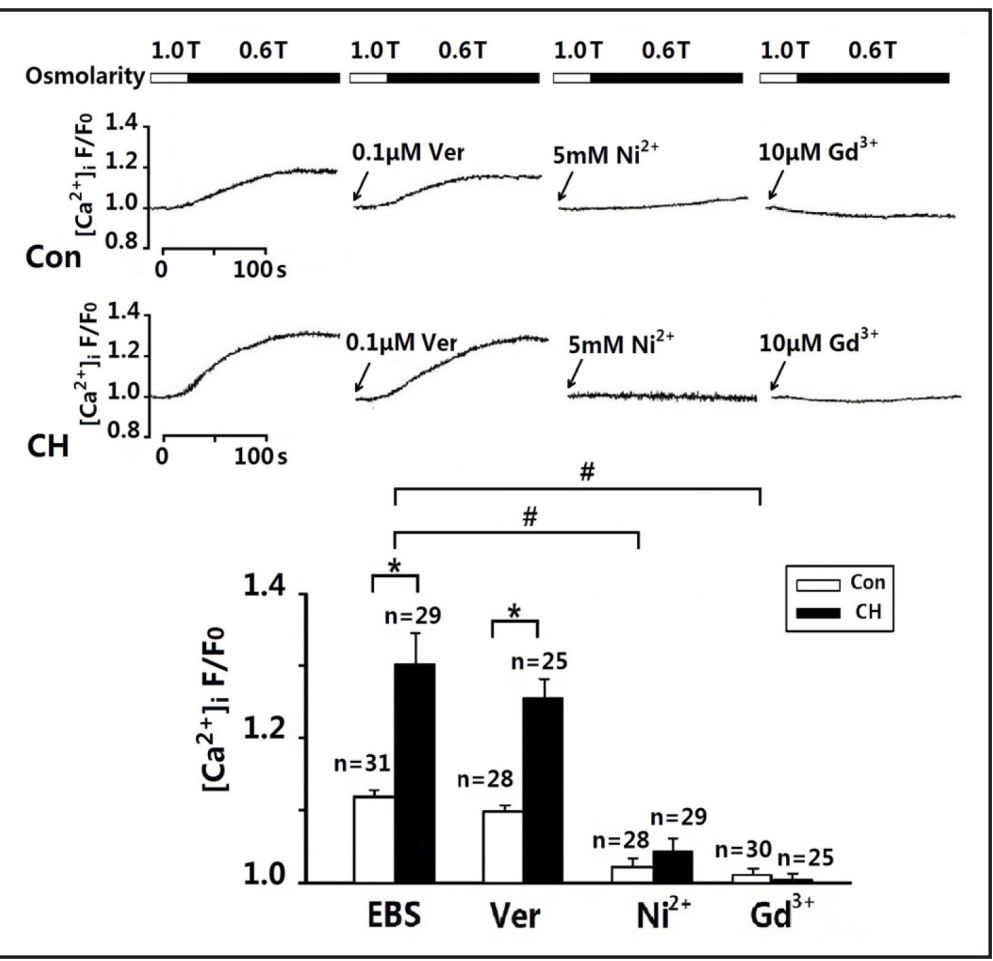

Fig. 3. Action potential of myocardium. (A) The cardiac hypertrophy $(\mathrm{CH})$ cells had longer action potential duration (APD) than control (Con) group in the empty bathing solution (EBS). The APD was prolongated, and the resting membrane potential (RMP) was depolarized when the preparation was stretched to $110 \%$ of the original length $\left(1.1 \mathrm{~L}_{0}\right)$. The administration of $\mathrm{Gd}^{3+}(10 \mu \mathrm{mol} / \mathrm{L})$ decreased the APD and hyperpolarized the RMP. (B) The increases of the $\mathrm{APD}_{50}$ induced by stretching $\left(\triangle \mathrm{APD}_{50}\right)$. (C) The changes in RMP. $\mathrm{n}=10$ per group, $* P<0.05$ vs. Con.

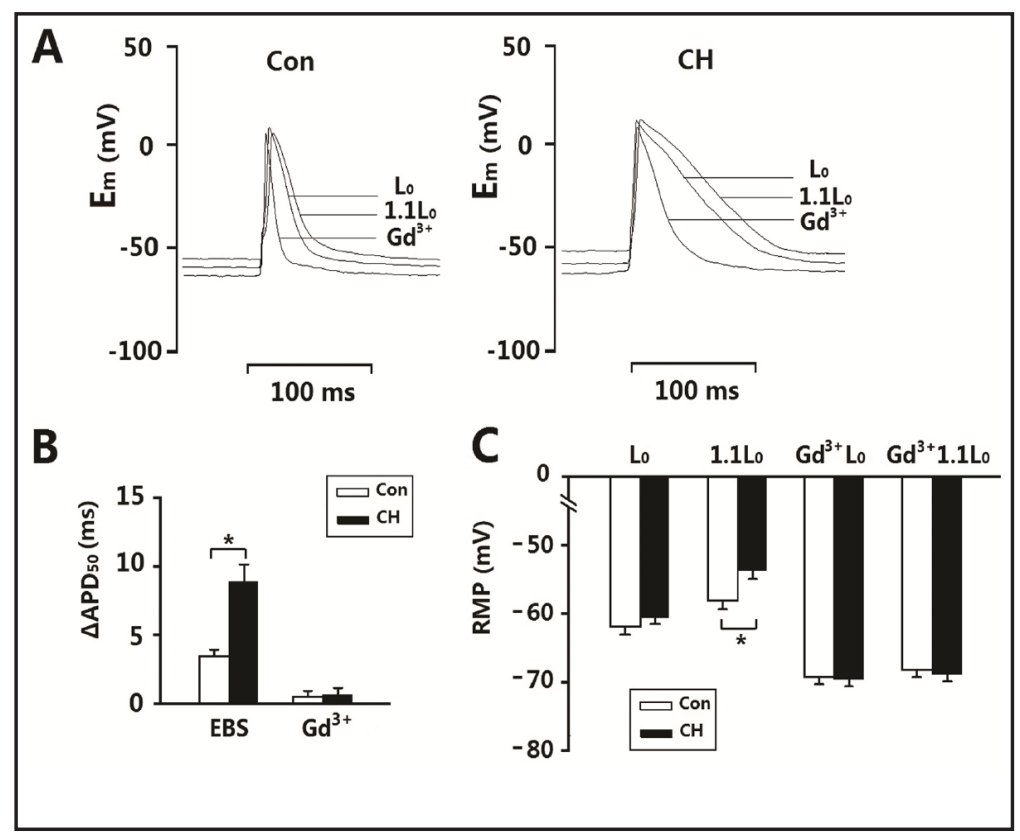

Although $\mathrm{Gd}^{3+}$ has an inhibitory effect on the $\mathrm{Na}^{+}-\mathrm{Ca}^{2+}$ exchanger current, most of the NCX1 are not blocked by Gd ${ }^{3+}$ at the concentration of $10 \mu \mathrm{mol} / \mathrm{L}$ [22]. The results confirmed that $\mathrm{Na}^{+}$was the main carrier of the stretch-activated currents $[11,23]$, the intracellular $\mathrm{Ca}^{2+}$ increased predominantly through the NCX1, and the activity of the SACs increased in the hypertrophic myocardium.

\section{Action potential of myocardium}

After the action potential duration was to $50 \%$ repolarization $\left(\mathrm{APD}_{50}\right)$, the membrane potential was under $-30 \mathrm{mV}$, and the main $\mathrm{Ca}^{2+}$ entrance - L-type $\mathrm{Ca}^{5+}$ channels were 
Fig. 4. The contribution of the SACs to the length-dependent contractile force of myocardium. (A) After the muscle length increased $10 \%$ from the original length $\left(\mathrm{L}_{0}\right)$, the developed contractile force $\left(\mathrm{F}_{\text {dev }}\right)$ between the control (Con) and the cardiac hypertrophy (CH) group was undifferentiated in the empty bathing solution (EBS), but the difference of $\mathrm{F}_{\text {dev }}$ between the Con and $\mathrm{CH}$ groups became obvious in the presence of $\mathrm{Gd}^{3+}$ (10 $\mu \mathrm{mol} / \mathrm{L})$. (B) The summary of data showing the changes in $\mathrm{F}_{\text {dev }}$. $\mathrm{Gd}^{3+}$ suppressed $\mathrm{F}_{\text {dev }}$ in the $\mathrm{CH}$ group, and its efficacy was further enhanced by 0.1 $\mu \mathrm{mol} / \mathrm{L}$ verapamil (Ver). $\mathrm{n}=10$, $* P<0.05$ vs. Con; \# $P<0.05$ vs. Ver absence.

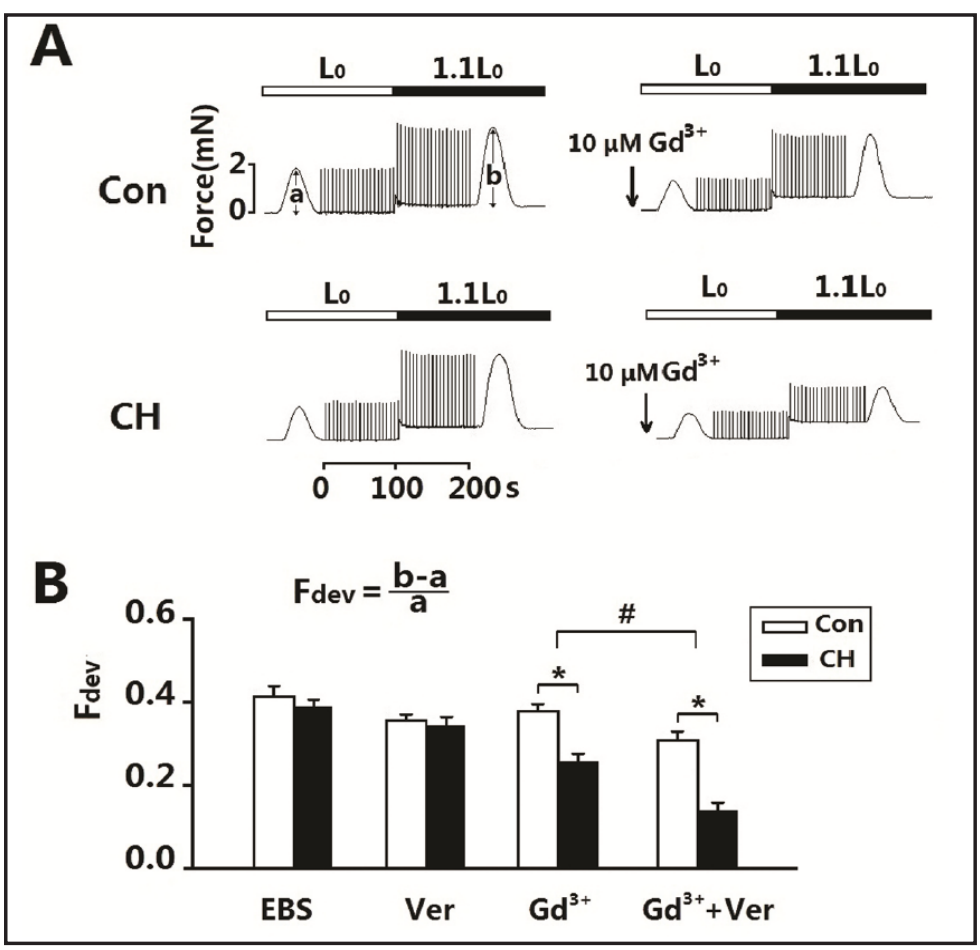

inactivated [24]. Thus the $\mathrm{APD}_{50}$ of ventricular myocytes, which best reflects the contribution of the L-type $\mathrm{Ca}^{2+}$ current [19], were measured and reported in Fig. 3. The results revealed that the hypertrophic myocardium had longer action potential duration (APD) than normal (before stretched, $\mathrm{APD}_{50} \mathrm{CH} 37.22 \pm 1.23 \mathrm{~ms}$ vs. control $18.14 \pm 0.78 \mathrm{~ms} ; \mathrm{n}=10, P<0.05$ ), mainly because of the significantly decreased transient outward $\mathrm{K}^{+}$current density in the hypertrophied cells [25]. The $\mathrm{APD}_{50}$ were prolongated by stretching in both groups because of the stretch-activated inward currents [23], and shortened by $\mathrm{Gd}^{3+}$. The increases of $\mathrm{APD}_{50}$ induced by stretching $\left(\triangle A P D_{50}\right)$ in the $\mathrm{CH}$ group were more significant than those in the control group (Fig. 3B). The administration of $\mathrm{Gd}^{3+}$ decreased the APD and restrained the prolongation induced by stretching.

The resting membrane potential (RMP) was depolarized during stretching. The amplitude of depolarization in the $\mathrm{CH}$ group was more significant than that in the control group (Fig. 3C). Significant $\mathrm{Na}^{+}$entry through the TRPCs may cause membrane depolarization and activation of the L-type $\mathrm{Ca}^{2+}$ channels, contributing to the $\mathrm{Ca}^{2+}$ influx [26]. Thus the increased activity of the SACs contributied to the $\mathrm{Ca}^{2+}$ influx for the contractile force in the hypertrophic myocardium. The administration of $\mathrm{Gd}^{3+}$ hyperpolarized the RMP and restrained the depolarization induced by stretching in both groups. In our observation, neither the AP configuration nor the APD was obviously affected by $0.1 \mu \mathrm{mol} / \mathrm{L}$ Ver.

Role of SACs in length-dependent contractile force

When the muscles were stretched from $\mathrm{L}_{0}$ to $1.1 \mathrm{~L}_{0}$, the developed contractile force $\left(\mathrm{F}_{\text {dev }}\right)$ of the control and the $\mathrm{CH}$ groups was undifferentiated in the Tyrode's solution. After the SACs were blocked by $\mathrm{Gd}^{3+}$, the increases of $\mathrm{F}_{\text {dev }}$ were different (Fig. 4), and obviously decreased in the hypertrophic myocardium. The administration of $0.1 \mu \mathrm{mol} / \mathrm{L}$ Ver decreased the basal contraction force but did not affect the increase of $F_{\text {dev }}$ in both groups. But Ver enhanced the effect of $\mathrm{Gd}^{3+}$ in suppressing the increase of $\mathrm{F}_{\text {dev }}$ especially in the hypertrophic myocardium.

\section{Role of SACs in the Frank-Starling effect}

The Frank-Starling curves of control and $\mathrm{CH}$ hearts were similar when perfused with Tyrode's solution, but the ascending limb of curves in the $\mathrm{CH}$ group was decreased in the presence of $10 \mu \mathrm{mol} / \mathrm{L} \mathrm{Gd}^{3+}$. Compared with the control group, a more serious decline 
Fig. 5. The Frank-Starling curves for the control (Con) and the cardiac hypertrophy $(\mathrm{CH})$ group hearts. The ascending limb of curves in the $\mathrm{CH}$ heart was significantly suppressed by $\mathrm{Gd}^{3+}(10 \mu \mathrm{mol} / \mathrm{L})$. $\mathrm{n}=10,{ }^{*} P<0.05$ vs. Con; $\# P<0.05$ vs. Con $\mathrm{Gd}^{3+}$.

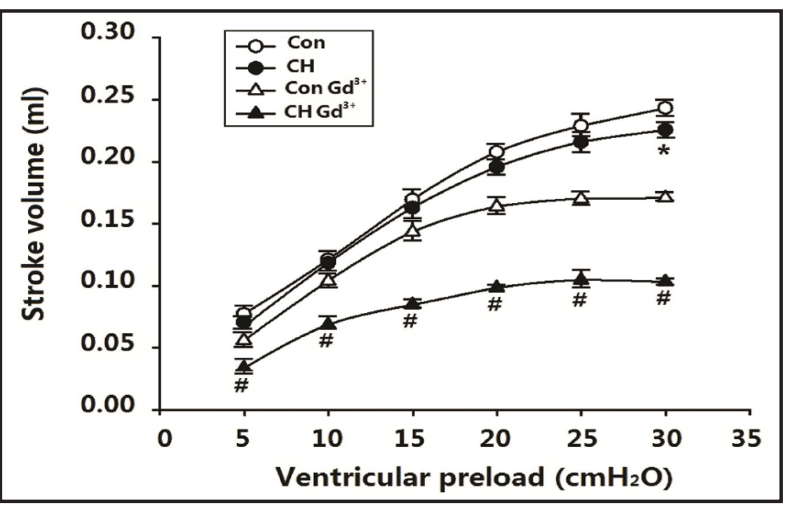

induced by $\mathrm{Gd}^{3+}$ was observed in the $\mathrm{CH}$ group (Fig. 5). The results demonstrated that the SACs enhanced the Frank-Starling effect in the hypertrophic heart, and that the contribution of the SACs to the systolic function was more significant in the hypertrophic myocardium.

\section{Discussion}

Normal cardiac systolic function obeys the Frank-Starling mechanism: when the heart muscle is stretched, it increases the force of contraction so that cardiac output matches the venous return on a nearly beat-to-beat basis [8]. The ascending limb of the Frank-Starling curves declines with the occurrence of systolic dysfunction. Many studies indicated that cations entering from the SACs contributed to the length-dependent contractile force [7-9]. The experiments confirmed that the main carrier of $I_{\mathrm{SAC}}$ in rat cardiac myocyte was $\mathrm{Na}^{+}$, and in the range of strain available, the change in $I_{\mathrm{SAC}}$ was approximately linear with both sarcomere length and strain $[11,23]$. The amplitude of $I_{\mathrm{SAC}}$ in the ventricular myocyte increased with hypertrophy [11], and the increased $\left[\mathrm{Na}^{+}\right]_{\mathrm{i}}$ caused $\mathrm{Ca}^{2+}$ influx through NCX1, especially in the myocardium with prolonged APD in heart failure [27, 28].

The intracellular $\mathrm{Ca}^{2+}$ increased when the myocardium was stretched, which indicated that the SACs, types of mechanosensitive, non-selective cation channels contributed to the cardiac systolic function in addition to the effect of changes in overlap between the thin and thick filaments $[6,7,9]$. The TRPCs, NCX1 and L-type $\mathrm{Ca}^{2+}$ channel are involved in the intracellular $\mathrm{Ca}^{2+}$ transient as follows: the TRPCs are functionally coupled to NCX1, and the substantial $\mathrm{Na}^{+}$entry through the TRPC-encoded non-selective cation channels, which causes $\mathrm{Ca}^{2+}$ influx to extrude $\mathrm{Na}^{+}$from the cell. The activation of the TRPC channels may induce membrane depolarization and cause the opening of the L-type $\mathrm{Ca}^{2+}$ channel $[26$, 29]. TRPC1 is hypothesized to be the primary component of the SACs by the following mechanism: $I_{\text {SAC }}$ was increased when TRPC1 was upregulated [2], reducing the expression of TRPC1 by the antisense morpholinos inhibited $\mathrm{Ca}^{2+}$ influx [30]; the homozygous TRPC1 knockout mice cardiomyocytes failed to respond to the different forms of stretching (swelling and positive pressure), as indicated by the lack of SACs [31]. Isoproterenol was used to induce the necrosis of rat myocardium and cardiac dysfunction, and the surviving cell hypertrophied because of the increased workload [32]. The expression of TRPC1 increased in the hypertrophic myocardium, and we considered that the activity of SACs increased due to TRPC1 upregulation, because TRPC3/6 and NCX1 were unchanged.

The APD prolongation and membrane depolarization caused by the inward currents from the SACs promoted substantial $\mathrm{Ca}^{2+}$ entry into the cell through the NCX1 and L-type $\mathrm{Ca}^{2+}$ channel $[26,28]$. The amplitude of the APD prolongation and membrane depolarization were more significant in the hypertrophic myocardium, which facilitated more $\mathrm{Ca}^{2+}$ influx compared with the normal myocardium. The contractile functions of the $\mathrm{CH}$ and control groups were similar before the SACs were blocked. In the presence of $\mathrm{Gd}^{3+}$, the lengthdependent contractile force was significantly depressed in the $\mathrm{CH}$ group, and the ascending limb of Frank-Starling curves in the $\mathrm{CH}$ group declined dramatically. The above results 
demonstrated that the increased $\left[\mathrm{Ca}^{2+}\right]_{\mathrm{i}}$ through the SACs had a significant contribution to maintaining the cardiac contractile function in the hypertrophic myocardium, and decompensation occurred when the SACs were blocked.

Although isoproterenol-induced cardiac hypertrophy is similar to hypertrophic cardiomyopathy, the findings of our study are limited to the model we used because the changes of the TRPCs vary in cardiovascular diseases. Different membrane channel protein families (including the TRPCs, TRPMs and Piezos, etc) have been proposed as participants in forming the mechanosensitive $\mathrm{Ca}^{2+}$ permeant cation channel [33-35]. Multiple independent studies have shown that TRPC1 is the primary component of the SACs, but the accurate structure of the SACs is still unclear; the role of TRPC1 in forming the SACs may not be exactly identical in different cells [33]. Changes in a specific protein expression (TRPC1) and a channel activity (SACs) correlating with a specific pathological process does not mean that the two are the same.

We conclude that the hypertrophic myocardium expresses more TRPC1 to enhance the capacity of the SACs and facilitate $\mathrm{Ca}^{2+}$ influx to maintain the contractile force when the preload increases, which is a type of compensatory mechanism to avoid heart failure occurring. These findings may provide a new perspective on the physiological function of the TRPCs in the myocardial cell. It suggests that promoting the activation of the TRPCs could be a potential therapeutic target for cardiac systolic dysfunction.

\section{Conflicts of Interest}

The authors have no conflicts of interest to disclose.

\section{Acknowledgements}

This work was supported by the 43rd Scientific Research Foundation for the Returned Overseas Chinese Scholars, Ministry of Education of China and the Central Authorities of the Institution of Higher Learning of Scientific Research Special Fund of China (2011TS071).

\section{References}

1 Minke B: The history of the drosophila TRP channel: the birth of a new channel superfamily. J Neurogenet 2010;24:216-233.

2 Maroto R, Raso A, Wood TG, Kurosky A, Martinac B, Hamill OP: TRPC1 forms the stretch-activated cation channel in vertebrate cells. Nat Cell Biol 2005;7:179-185.

-3 Spassova MA, Hewavitharana T, Xu W, Soboloff J, Gill DL: A common mechanism underlies stretch activation and receptor activation of TRPC6 channels. Proc Natl Acad Sci U S A 2006;103:16586-16591.

4 Goel M, Zuo CD, Sinkins WG, Schilling WP: TRPC3 channels colocalize with $\mathrm{Na}^{+} / \mathrm{Ca}^{2+}$ exchanger and $\mathrm{Na}^{+}$ pump in axial component of transverse-axial tubular system of rat ventricle. Am J Physiol Heart Circ Physiol 2007;292:H874-H883.

-5 Eder P, Probst D, Rosker C, Poteser M, Wolinski H, Kohlwein SD, Romanin C, Groschner K: Phospholipase C-dependent control of cardiac calcium homeostasis involves a TRPC3-NCX1 signaling complex. Cardiovasc Res 2007;73:111-119.

6 Allen DG, Jewell BR, Murray JW: The contribution of activation processes to the length-tension relation of cardiac muscle. Nature 1974;248:606-607.

7 Lab MJ, Zhou BY, Spencer CI, Horner SM, Seed WA: Effects of gadolinium on length-dependent force in guinea-pig papillary muscle. Exp Physiol 1994;79:249-255.

8 Cannell MB: Pulling on the heart strings: a new mechanism within Starling's law of the heart? Circ Res 2009;104:715-716.

9 Ward ML, Williams IA, Chu Y, Cooper PJ, Ju YK, Allen DG: Stretch-activated channels in the heart: contributions to length-dependence and to cardiomyopathy. Prog Biophys Mol Biol 2008;97:232-249.

10 Ohba T, Watanabe H, Murakami M, Takahashi Y, Iino K, Kuromitsu S, Mori Y, Ono K, Iijima T, Ito H: Upregulation of TRPC1 in the development of cardiac hypertrophy. J Mol Cell Cardiol 2007;42:498-507.

11 Kamkin A, Kiseleva I, Isenberg G: Stretch-activated currents in ventricular myocytes: amplitude and arrhythmogenic effects increase with hypertrophy. Cardiovasc Res 2000;48:409-420. 


\section{Cellular Physiology Cell Physiol Biochem 2013;32:951-959 and Biochemistry \\ Chen/Xiao/Wang/Xu/Gao/Wang: TRPC1 for Myocardial Contraction}

12 Krenek P, Kmecova J, Kucerova D, Bajuszova Z, Musil P, Gazova A, Ochodnicky P, Klimas J, Kyselovic J: Isoproterenol-induced heart failure in the rat is associated with nitric oxide-dependent functional alterations of cardiac function. Eur J Heart Fail 2009;11:140-146.

13 Takeshita D, Shimizu J, Kitagawa Y, Yamashita D, Tohne K, Nakajima-Takenaka C, Ito H, Takaki M: Isoproterenol-induced hypertrophied rat hearts: does short-term treatment correspond to long-term treatment? J Physiol Sci 2008;58:179-188.

14 Hu ZL, Huang C, Fu H, Jin Y, Wu WN, Xiong QJ, Xie N, Long LH, Chen JG, Wang F: Disruption of PICK1 attenuates the function of ASICs and PKC regulation of ASICs. Am J Physiol Cell Physiol 2010;299:C1355-C1362.

15 Clemo HF, Baumgarten CM: Swelling-activated Gd $\mathrm{G}^{3+}$-sensitive cation current and cell volume regulation in rabbit ventricular myocytes. J Gen Physiol 1997;110:297-312.

-16 Suchyna TM, Johnson JH, Hamer K, Leykam JF, Gage DA, Clemo HF, Baumgarten CM, Sachs F: Identification of a peptide toxin from Grammostola spatulata spider venom that blocks cation-selective stretch-activated channels. J Gen Physiol 2000;115:583-598.

17 Lamberts RR, Van Rijen MH, Sipkema P, Fransen P, Sys SU, Westerhof N: Coronary perfusion and muscle lengthening increase cardiac contraction: different stretch-triggered mechanisms. Am J Physiol Heart Circ Physiol 2002;283:H1515-H1522.

18 Wasserstrom JA, Vites AM: The role of $\mathrm{Na}^{+}-\mathrm{Ca}^{2+}$ exchange in activation of excitation-contraction coupling in rat ventricular myocytes. J Physiol 1996;493:529-542.

19 Fauconnier J, Bedut S, Le Guennec JY, Babuty D, Richard S: $\mathrm{Ca}^{2+}$ current-mediated regulation of action potential by pacing rate in rat ventricular myocytes. Cardiovasc Res 2003;57:670-680.

20 Muller-Strahl G, Hemker J, Zimmer HG: Comparison between left and right heart function in the isolated biventricular working rat heart. Exp Clin Cardiol 2002;7:7-19.

21 Nakajima-Takenaka C, Zhang GX, Obata K, Tohne K, Matsuyoshi H, Nagai Y, Nishiyama A, Takaki M: Left ventricular function of isoproterenol-induced hypertrophied rat hearts perfused with blood: mechanical work and energetics. Am J Physiol Heart Circ Physiol 2009;297:H1736-H1743.

22 Zhang YH, Hancox JC: Gadolinium inhibits $\mathrm{Na}^{+}-\mathrm{Ca}^{2+}$ exchanger current in guinea-pig isolated ventricular myocytes. Br J Pharmacol 2000;130:485-488.

23 Zeng T, Bett GC, Sachs F: Stretch-activated whole cell currents in adult rat cardiac myocytes. Am J Physiol Heart Circ Physiol 2000;278:H548-H557.

24 Yuan W, Ginsburg KS, Bers DM: Comparison of sarcolemmal calcium channel current in rabbit and rat ventricular myocytes. J Physiol 1996;493:733-746.

25 Yang X, Salas PJ, Pham TV, Wasserlauf BJ, Smets MJ, Myerburg RJ, Gelband H, Hoffman BF, Bassett AL: Cytoskeletal actin microfilaments and the transient outward potassium current in hypertrophied rat ventriculocytes. J Physiol 2002;541:411-421.

26 Wang YX, Zheng YM: Molecular expression and functional role of canonical transient receptor potential channels in airway smooth muscle cells. Adv Exp Med Biol 2011;704:731-747.

27 Kang TM, Hilgemann DW: Multiple transport modes of the cardiac $\mathrm{Na}^{+} / \mathrm{Ca}^{2+}$ exchanger. Nature 2004;427:544-548.

28 Weber CR, Piacentino VR, Houser SR, Bers DM: Dynamic regulation of sodium/calcium exchange function in human heart failure. Circulation 2003;108:2224-2229.

29 Chen JB, Tao R, Sun HY, Tse HF, Lau CP, Li GR: Multiple $\mathrm{Ca}^{2+}$ signaling pathways regulate intracellular $\mathrm{Ca}^{2+}$ activity in human cardiac fibroblasts. J Cell Physiol 2010;223:68-75.

-30 Kerstein PC, Jacques-Fricke BT, Rengifo J, Mogen BJ, Williams JC, Gottlieb PA, Sachs F, Gomez TM: Mechanosensitive TRPC1 channels promote calpain proteolysis of talin to regulate spinal axon outgrowth. J Neurosci 2013;33:273-285.

-31 Seth M, Zhang ZS, Mao L, Graham V, Burch J, Stiber J, Tsiokas L, Winn M, Abramowitz J, Rockman HA, Birnbaumer L, Rosenberg P: TRPC1 channels are critical for hypertrophic signaling in the heart. Circ Res 2009;105:1023-1030.

-32 Marques FD, Ferreira AJ, Sinisterra RD, Jacoby BA, Sousa FB, Caliari MV, Silva GA, Melo MB, Nadu AP, Souza LE, Irigoyen MC, Almeida AP, Santos RA: An oral formulation of angiotensin-(1-7) produces cardioprotective effects in infarcted and isoproterenol-treated rats. Hypertension 2011;57:477-483.

33 Maroto R, Kurosky A, Hamill OP: Mechanosensitive $\mathrm{Ca}^{2+}$ permeant cation channels in human prostate tumor cells. Channels (Austin) 2012;6:290-307.

-34 Wei C, Wang X, Chen M, Ouyang K, Song LS, Cheng H: Calcium flickers steer cell migration. Nature 2009;457:901-905.

-35 Coste B, Mathur J, Schmidt M, Earley TJ, Ranade S, Petrus MJ, Dubin AE, Patapoutian A: Piezo1 and Piezo2 are essential components of distinct mechanically activated cation channels. Science 2010;330:55-60. 